\title{
Recent advances in the role of toll-like receptors and TLR agonists in immunotherapy for human glioma
}

\author{
Shuanglin Deng ${ }^{1,2}$, Shan Zhu', Yuan Qiao ${ }^{1}$, Yong-Jun Liu $^{3}$, Wei Chen ${ }^{4}$, Gang Zhao ${ }^{2 \bowtie}$, Jingtao Chen ${ }^{1 凶}$ \\ 1 Institute of Translational Medicine, the First Hospital, Jilin University, Changchun 130031, China \\ 2 Department of Neurosurgery, the First Hospital, Jilin University, Changchun 130031, China \\ ${ }^{3}$ Medlmmune, Gaithersburg, MD 20878, USA \\ ${ }^{4}$ Department of Hematology-Oncology and BMT Department of Pediatrics, University of Minnesota Medical School, \\ Minneapolis, MN 55455, USA \\ $\bowtie$ Correspondence: Gangzhao_12@sina.com (G. Zhao), jtchen@jlu.edu.cn (J. Chen) \\ Received August 25, 2014 Accepted September 30, 2014
}

\begin{abstract}
Gliomas are extremely aggressive brain tumors with a very poor prognosis. One of the more promising strategies for the treatment of human gliomas is targeted immunotherapy where antigens that are unique to the tumors are exploited to generate vaccines. The approach, however, is complicated by the fact that human gliomas escape immune surveillance by creating an immune suppressed microenvironment. In order to oppose the glioma imposed immune suppression, molecules and pathways involved in immune cell maturation, expansion, and migration are under intensive clinical investigation as adjuvant therapy. Toll-like receptors (TLRs) mediate many of these functions in immune cell types, and TLR agonists, thus, are currently primary candidate molecules to be used as important adjuvants in a variety of cancers. In animal models for glioma, TLR agonists have exhibited antitumor properties by facilitating antigen presentation and stimulating innate and adaptive immunity. In clinical trials, several TLR agonists have achieved survival benefit, and many more trials are recruiting or ongoing. However, a second complicating factor is that TLRs are also expressed on cancer cells where they can participate instead in a variety of tumor promoting activities including cell growth, proliferation, invasion, migration, and even stem cell maintenance. TLR agonists can, therefore, possibly play dual roles in tumor biology. Here, how TLRs and TLR agonists function in glioma biology and in anti-glioma therapies is summarized in an effort to provide a
\end{abstract}

current picture of the sophisticated relationship of glioma with the immune system and the implications for immunotherapy.

KEYWORDS glioma, toll-like receptor, agonist, central nervous system, immunotherapy

\section{INTRODUCTION}

Gliomas are the most common neoplasms occurring in the central nervous system (CNS), and are one of the most aggressive types of human cancer. Histological classification of gliomas according to the World Health Organization consists of grades I-IV (Louis et al., 2007), with grade I corresponding to a benign tumor and grades II to IV increasing in malignancy. Grade III and grade IV gliomas are considered malignant and have a very poor prognosis. Glioblastoma multiforme (GBM; grade IV), is the most aggressive form of human glioma, and the mean survival of these patients remains dismally at approximately 12 months despite intensive and comprehensive therapies (Louis et al., 2007).

One of the more promising therapeutic strategies for the treatment of human gliomas is immunotherapy. Elucidation of the molecular basis for immune response is, therefore, currently under rigorous analysis. Molecules fundamental to eliciting an immune response in various immune cell types are toll-like receptors (TLRs) and correspondingly, their receptor agonists. TLRs are an evolutionarily conserved family of pattern-recognition receptors with 10 functional members (TLR 1-10) in human that are expressed on a 
variety of immune cell types. Toll-like receptor agonists are pathogen-associated molecular patterns (PAMPs) that bind to TLRs with specificity and in a typical scenario, initiate an immune response. The complicating factor in glioma biology is that the same TLRs are also found to be expressed on glioma cells themselves. Further complicating the issue is the fact that specific family members, such as TLR2, TLR4, and TLR9, following detection of corresponding TLR agonists, have a tumor promoting role in the biology of these tumors.

Triggering TLRs to generate an immune response is therefore a primary goal in immunotherapy for cancer in general. The design of current strategies is to exploit antigens uniquely presented by a tumor type so that the vaccine will be specific, but to use TLR agonists as adjuvants to potentially enhance the response. TLR agonists have been well-described and furthermore have greater affinities for different TLRs so that they can be used to specifically probe immune response in vivo. Currently, agonists, such as BCG (TLR1, 2, 4, and 6), MPL (TLR4), poly(I:C) (TLR3), imiquimod (TLR7), and CpG (TLR9), have been tested and reported to initiate therapeutic effects to varying degrees in clinical trials for colon cancer (Vermorken et al., 1999), urothelial carcinoma (Sharma et al., 2008), non-small-cell lung cancer (Vansteenkiste et al., 2007), lymphoma (Brody et al., 2010), melanoma (Adams et al., 2008), and a number of other cancers.

Many TLR agonists have been introduced into animal models of glioma to investigate immunotherapies and their underlying mechanisms. Since the expression of TLRs on glioma cells has been associated with some tumor promoting activities, it is important to summarize the major findings concerning TLRs and TLR agonists in glioma models for a more comprehensive view of this field.

\section{TLRS AND TLR AGONISTS}

The Toll gene was initially described in Drosophila and found to mediate dorsoventral embryonic development and innate immune functions (Anderson et al., 1985). The human homolog of Toll was subsequently cloned in 1997, and its role in the human adaptive immune response was determined (Medzhitov et al., 1997). Shortly thereafter, the first toll-like receptor, TLR4, was discovered (Poltorak et al., 1998). Currently, a total of $13 T L R$ genes have been identified in human and mouse genomes; TLR1-10 are functional in human, and TLR1-9 and TLR11-13 are functional in mouse.

Expression of the TLRs varies with immune cell type. Among human antigen presenting cells (APCs), TLR7, 9, and 10 are expressed on plasmacytoid dendritic cells (pDCs), whereas all TLRs, with the exception of TLR9, are expressed on myeloid derived DCs (mDCs). In human adaptive immune system, TLR1, 2, 3, 4, 5, 7, and 9 (Caron et al., 2005; Hornung et al., 2002; Zarember and Godowski,
2002) are expressed on T cells, and TLR5 and 8 (Crellin et al., 2005; Kabelitz, 2007) are expressed on regulatory $\mathrm{T}$ cells (Treg), a cell type critical to the maintenance of immune homeostasis. Finally, activated and memory B cells express significant levels of TLR1, 6, 7, 9, and 10 but low levels of TLR2 (Agrawal and Gupta, 2011; Bernasconi et al., 2003; Hornung et al., 2002; Mansson et al., 2006).

TLR agonists are generally microbial molecules that stimulate TLR receptors to initiate specific immunoactivity. The most frequently studied of these agonists include lipopolysaccharides (LPS; TLR4 agonist), lipopeptides (TLR1, TLR2, and TLR6 agonists), flagellin (TLR5 agonist), single stranded (TLR7 and TLR8 agonist) or double stranded (ds) RNA (TLR3 agonist), and DNA containing the CpG motif (TLR9 agonist). Recent studies indicate that endogenous molecules released from stressed or dead cells such as heat shock proteins (HSP; TLR2 and TLR4) and high mobility group box 1 (HMGB1; TLR2 and TLR4) are also important TLR agonists (Asea et al., 2002; Kepp et al., 2011).

When TLR agonists bind to their receptors, the bulk of downstream signaling is generally executed through one of two different pathways, myeloid differentiation factor 88 (MyD88)-dependent and MyD88-independent. The former leads to early activation of NF-KB, MAPK, and transcription of pro-inflammatory cytokines, chemokines, and cytosolic enzymes, while the latter results in the activation of late phase NF-KB and the interferon (IFN) regulatory factors responsible for type I IFN expression (Akira and Takeda, 2004; O'Neill and Bowie, 2007).

\section{EXPRESSION OF TLRS IN MICROGLIA AND GLIOMA CELLS}

For TLR agonist-based cancer immunotherapy, it is important to carefully evaluate the role of TLR agonist in terms of both systemic and regional effects in order to deliver the most effective treatment with the least number of side effects. Furthermore, while TLR expression on the immune cells generally supports the therapeutic purpose, the expression on cancer cells (Arunkumar et al., 2013; CherfilsVicini et al., 2010; Huang et al., 2007; Kundu et al., 2008; Nomi et al., 2010; Salaun et al., 2006) can corrupt the process. TLRs are expressed on both the tumor cells and microglia, a normal glial cell that makes up a major cellular component of human glioma (da Fonseca and Badie, 2013). The following section summarizes TLR expression patterns and related biological responses in order to predict potential regional effects elicited by TLR agonists in TLR agonistbased glioma immunotherapy.

\section{TLR expression on glioma cells}

TLR2, TLR4, and TLR9 have been under investigation for expression on glioma cells, and their contribution to tumor development has been mostly described as tumor promoting. 


\section{TLR2}

The expression levels of $T L R 2$ are substantially elevated in patient glioma biopsies and inversely correlate with patient survival (Vinnakota et al., 2013). TLR2 expression has also been detected in human glioblastoma U87 cells with touchdown PCR (Haghparast et al., 2011) and subsequently linked to tumor promotion. When cells were treated with the TLR2 agonist peptidoglican (PGN), TLR2 initiated signaling through the activation of NF-KB, which ultimately led to increased cell growth (Echigo et al., 2012).

\section{TLR4}

TLR4 RNA and/or protein expression has been detected in U118, U87, A172, and LN229 glioma cell lines (Gupta et al., 2013; Sarrazy et al., 2011; Tewari et al., 2012). Protein expression in primary biopsies from glioblastoma patients has been found to be elevated relative to adjacent nonneoplastic tissue by immunohistochemistry and Western blot analysis (Tewari et al., 2012). In in vitro studies, different tumor promoting effects were directly observed when cells were exposed to the TLR4 agonist LPS. First, the proliferation of U118 and U87 and the invasion of U87 cells (Sarrazy et al., 2011) were enhanced. The expression of the metalloproteinase, MMP-9, which is essential for increased invasion of the cells, was also elevated in U87 in response to stimulation by LPS. Second, signaling through TLR4 was found to be involved in mechanisms regulating cell survival, migration and immune evasion, and resistance to TNF- $\alpha$ treatment. TLR4 was either directly involved in these processes or influenced their outcome.

Enhanced invasion mediated by TLR4 is potentially the result of an intriguing mechanism that involves the binding of extracellular heat shock protein 90 (HSP90) to TLR4 with subsequent transactivation of epidermal growth factor receptor (EGFR). HSP90 is a major protein produced in response to tumor cell stress and is found at increased extracellular levels in the tumor environment. In this mechanism, HSP90 binds to TLR4, which leads to activation of EGFR and an increase in intracellular calcium levels necessary to promote tumor cell migration (Thuringer et al., 2011).

The release of specific cytokines that protect cells from apoptosis or lead to the ability of tumor cells to altogether evade immune detection may also be due to the expression of TLR4 on glioma cells. The resistance of gliomas to apoptosis, induced in one scenario by TNF- $\alpha$, is possibly due to the release of cytokines IL-6, IL-8, and MCP-1, in fact, in response to TNF- $\alpha$ treatment (Tewari et al., 2009). IL-8 is associated with hypoxia induced glioma progression (Brat et al., 2005), and MCP-1 is responsible for the tumor promoting activity of microglia (Platten et al., 2003). In tumor cells, it is TLR4 that is activated by TNF- $\alpha$, via TIR-domaincontaining adapter-inducing interferon- $\beta$ (TRIF) dependent pathway, forming a feed-forward loop with TNF- $\alpha$, which triggers the release of these cytokines (Tewari et al., 2012).
$\mathrm{IL}-1 \beta$ is an additional cytokine secreted by glioma cells subsequent to TNF- $\alpha$ treatment. This cytokine actually induces TLR4 expression, via hypoxia inducible factor 1- $\alpha$ (HIF-1 $\alpha$ ), which results in the elevation of HMGB1 in glioma cells. The upregulation of TLR4 and HMGB1 is synergistic and results in the increase of HLA-G, a non-classical HLA class I antigen that participates in glioma immune evasion (Gupta et al., 2013).

One potential way to bypass these particular challenges due to the expression of TLR4 on glioma cells is through the activation of the Fas pathway. Engagement of this pathway generally leads to apoptosis in a variety of cancers (Shinohara et al., 2000), including glioma (Zhao et al., 2007). Interestingly, when TLR4 and Fas were simultaneously activated, the tumor promoting capabilities of TLR4 were lost, as well as the increased expression of MMP-9, which was necessary for the U87 cell invasion stimulated by LPS alone. The molecular details of how these two molecules/ pathways functionally intersect requires further investigation, however, to be of therapeutic value (Sarrazy et al., 2011).

\section{TLR9}

TLR9 is expressed on human cell lines U251, U87, and the murine cell line $\mathrm{C} 6$. This receptor is also found in primary human glioma biopsies and isolated human glioma stem-like cells. Clinically, increased expression of TLR9 has been associated with higher tumor grade and worse prognosis. Functionally, studies have demonstrated that TLR9 mediates the properties of enhanced invasion and proliferation. Studies have demonstrated that the TLR9 agonist, CpG dinucleotide, enhances cell invasion in vitro through TLR9 (Wang et al., 2010). In addition, there is a correlation between TLR9 and the metalloproteinases MMP2 and MMP9 in clinical samples (Leng et al., 2012; Wang et al., 2010). Activated TLR9 also promoted growth of glioma stem-like cells through the activation of STAT3 signaling in vitro, which is a pathway participating in numerous tumor promoting activities (Herrmann et al., 2014). In contrast, CpG dinucleotides also function as a radio-sensitizer potentially through TLR9. CpG raises nitrogen monoxide (NO) levels in CpG treated U87 cells through TLR9 mediated NF-KB signaling, thereby potentiating the radiosensitivity of the cells in vitro ( $\mathrm{Li}$ et al., 2012).

How TLRs might be controlled by other events occurring during tumor development is illustrated by the regulation of TLR9 by insulin growth factor 1 (IGF1). IGF-1 is a wellknown growth factor associated with tumor growth. In glioma cells, IGF-1 induced TLR9 through HIF-1a signaling, mediated by Ras and calmodulin dependent kinase II (CaMK II). Enhanced expression of TLR9 induced by IGF-1 resulted in the secretion of $\mathrm{IL}-1 \beta, \mathrm{IL}-6, \mathrm{IL}-8$, and the elevation of CXCR-4, a receptor that plays an important role in cell migration. CXCR-4 may thus underlie the mechanism for TLR9 enhancement of the metastatic potential of glioma cells (Sinha et al., 2011). 
In summary, TLR agonists bring potential risks to immunotherapies because these receptors can also initiate tumor promoting biological processes when expressed by glioma cells. For this reason, thorough studies of TLR expression in glioma cells, the effect of different TLR agonists for the same TLR or different TLRs on glioma cells in vitro, and the underlying molecular mechanisms are critical for the proper guidance and design of therapies.

\section{TLRs and microglia}

Microglia is a type of tissue resident macrophage of myeloid origin and perform brain specific immune surveillance. These glial cells heavily infiltrate gliomas, and can constitute up to $30 \%$ of the infiltrating normal cell population (the stroma). The local density of microglia can be as great as 20 times higher in glioma than normal brain tissue (Hussain et al., 2006b). TLR2, 3, 4, and 9 are highly expressed on both human microglia in the normal brain parenchyma and tumor-infiltrating microglia. However, despite similar levels in TLR expression (Hussain et al., 2006b; Meng et al., 2008), the function of the infiltrating microglia is highly influenced by the tumor microenvironment.

TLRs play an important role in the regulation of microglial activity during gliomagenesis. For example, membrane type 1 matrix metalloproteinase (MT1-MMP) is a molecule in microglia that controls response to certain growth factors in neovascularization, and engagement of this molecule is one way that microglia contributes positively to glioma growth. Expression of TLR2 in microglia is necessary for the activation of MT1-MMP by neighboring glioma cells, and the process is MyD88 dependent (Vinnakota et al., 2013). Based on these results and the fact that the molecule is highly expressed in human gliomas, TLR2 was examined as a potential biomarker, and its expression was found to be inversely correlated to patient survival (Vinnakota et al., 2013).

Microglia isolated from patient biopsies, however do retain their antitumor properties. Poly(l:C) stimulation polarized isolated microglia in vitro toward an antitumor M1-like profile which resulted in increased microglial production of inflammatory cytokines TNF- $\alpha$ and IL-12 (Kees et al., 2012). These supernatants induced apoptosis and inhibited migration of glioma cells. The experiment was also performed in the presence of glioma cells to determine how the tumor microenvironment influenced microglial function. When cocultured with glioma spheroids, poly(I:C) stimulated microglia were impaired with respect to their antitumor properties (Kees et al., 2012). Similar effects were observed when microglia was stimulated with a second TLR agonist, LPS. LPS also stimulated microglia to produce TNF- $\alpha$ in vitro, but glioma cells both through paracrine and direct cell-contact mechanisms, inhibited this effect. The study also revealed that the glioma cells induced microglia to secrete the antiinflammatory cytokine $\mathrm{IL}-10$ and to up-regulate STAT3 signaling activity, two activities that are tumor promoting (Kostianovsky et al., 2008).

TLRs mediate both tumor promoting and tumor inhibiting functions of microglia. Glioma cells skillfully usurp these glial cells for their growth promoting properties, and yet, microglia remains fundamentally unaltered with regard to their tumor inhibiting functions. Thus, microglia and TLR signaling are tools that may be manipulated for therapeutic purposes, particularly in light of the fact that these cells constitute a considerable fraction of human gliomas. Although engagement of TLR3 and TLR4 pathways alone, for example, may not be sufficient to eradicate tumors, targeting these receptors could be considered as a supplement to therapy until mechanisms of glioma cell suppression on microglia are more clearly understood.

\section{TLRS AND ANTI-GLIOMA IMMUNITY}

Local immune suppression is one part of the challenges that face immunotherapy; immune suppression is a systemic manifestation of cancer as well. Research efforts to boost the immune response in cancer patients are therefore also focused on more fundamental failures of the immune system in cancers. Here, TLR agonists in glioma immunotherapies have also been promising as tools to activate APCs and effector $\mathrm{T}$ cells, and in general to reverse glioma induced suppression of maturation of these cell types. The following content reviews recent advances that describe how TLRs and TLR agonists contribute to the development of anti-glioma immunity.

\section{TLRs and glioma antigen presentation}

DCs in the brain develop from pre-DCs located in meninges and choroid plexus (Anandasabapathy et al., 2011). Some investigators believe that DCs actually carry antigens from the CNS and migrate deep into the cervical lymph nodes (CLN) in order to activate the maturation of residing naive $\mathrm{T}$ cells (Karman et al., 2004). However, whether DC cells do migrate out of the CNS and how they do so, still remains controversial (Weller et al., 2009). Generally, DCs are thought to be the APCs fundamental to the development of effective anti-glioma immunity. Therefore, the role of TLR agonists in the maturation of DCs and the enhancement of their capacity for migration and antigen presentation is currently under rigorous investigation.

\section{TLRs and DC activation}

In contrast to its role in glioma-derived microglia, TLR2 expression on DCs is of potential benefit to immunogenic glioma cell lysis. Stimulation of the receptor by a corresponding endogenous or synthetic agonist has been shown to effectively initiate activation of DCs through NF-KB signaling. A novel method of locally producing a desired endogenous agonist was through gancyclovir mediated cell 
death of glioma cells expressing thymidine kinase from adenovirus. The release of HMGBI, a TLR2 agonist, from the dead glioma cells stimulated TLR2 (Foldi, 1999), and in combination with the local expression of the DC growth factor Fms-like tyrosine kinase 3 ligand (FIt3L) (Maraskovsky et al., 1996; Pulendran et al., 1997), led to expansion and activation of DCs resulting in the production of inflammatory cytokines TNF- $\alpha$ and IL-6 (Curtin et al., 2009) necessary to initiate an effective anti-glioma immune response (Ali et al., 2004). Weighing the balance in the dual character of TLR2 therefore appears to be an important consideration in the development of anti-glioma immunotherapies.

Systemic introduction of synthetic TLR agonists poly(l:C), imiquimod, and $\mathrm{CpG}$ also facilitated glioma antigen presentation. In an intracranial glioma model, imiquimod increased the number of DCs in the blood and CLN, and led to the doubling of the number of DCs in the brain (Xiong and Ohlfest, 2011). CpG was reported to activate and mature DCs as well (Krieg, 2006). Furthermore, a study in the murine model indicated that $\mathrm{CpG}$ achieved higher efficacy in the maturation of DCs when it was administered subcutaneously with tumor lysates. The combination exerted a synergistic effect in increasing the number of activated DCs in the cervical draining lymph nodes and eradicated intracerebral GL261 glioma cells in the mice (Wu et al., 2007). In a clinical trial, a DC vaccine with imiquimod or poly $(\mathrm{l}: \mathrm{C})$ as an adjuvant, boosted serum TNF- $\alpha$ and IL- 6 levels in glioblastoma patients (Prins et al., 2011).

\section{TLRs and glioma induced DC suppression}

The greatest challenge to immunotherapy is to overcome the local immunosuppressive microenvironment. TGF- $\beta$ secreted by tumor cells is one of the most important and extensively studied factors contributing to glioma microenvironment immune suppression (Kjellman et al., 2000). TGF- $\beta$ enables the tumor to efficiently evade immune surveillance by potently suppressing the maturation and function of DCs, which leads to a deficiency in antigen presentation and immune response (Grauer et al., 2007). Any effective immunotherapy, thus, must enable DCs to both mature and produce IL-12 in order to produce cytotoxic/mature T cells. TLR7 agonists that directly target DCs have been used in an attempt to reverse this immune suppression. R848 (TLR7/TLR8 agonist) in a cocktail with TNF- $\alpha$, IL-1 $\beta$, and IFN- $\gamma$ induced DC maturation and the production of IL-12 (Grauer et al., 2007).

Factors in addition to TGF- $\beta$ are also likely to contribute to the immune suppressive milieu in glioma, and through novel mechanisms. In one study, DCs isolated from fresh glioma biopsies were found to be refractory even to TLR agonist stimulation in vitro (Hussain et al., 2006a). A separate study identified lactate as an additional molecule that suppresses the immune response, and thus is also responsible for the resistance of DCs to TLR agonist stimulation (Chirasani et al., 2013). Lactate is abundant in glioma and most aggressively proliferating tumors (Walenta and Mueller-Klieser, 2004). Lactate decreased IL-12 production from mouse intracranial glioma derived DCs stimulated by R848, and even altered the function of the agonist, which resulted in the activation of STAT-3 signaling in DCs and subsequent suppression of their maturation. Small molecule inhibition of lactate enabled the TLR7/8 agonist R848 to stimulate secretion of IL-12 by DC in the glioma environment thereby alleviating immune suppression (Chirasani et al., 2013).

\section{TLRs and anti-glioma immune response}

After successful antigen presentation by DCs, effector T cells are activated to kill glioma cells. Their levels are subsequently redistributed in the tumor, brain, CLNs, and blood. TLR agonists delivered either systemically or locally, with or without tumor lysate/antigens, have achieved observable changes in the levels of these immune cell types in a variety of preclinical murine glioma models, that resulted in either eradication of the tumor or suppression of tumor growth. The main players involved in anti-glioma TLR immunotherapy are $\mathrm{CD}^{+} \mathrm{T}$ cells, which are assisted by $\mathrm{CD} 4^{+} \mathrm{T}$ cells. In certain studies however, the effector cells are not limited to the adaptive immunity. Members of the innate immune system, such as NK cells, also make important contributions depending on the agonist used and the therapeutic approach chosen (Alizadeh et al., 2010; Zhao et al., 2011). Cytokine changes can be associated with tumor suppression and under certain conditions, present independent factors that must be taken into consideration. Positive immunotherapeutic roles elicited through a variety of mechanisms have involved TLR2, TLR3, TLR4, TLR7, and TLR9 in these cell types.

\section{TLR2}

Bacterial lipoprotein (TLR2 agonist) administered with antigen-specific T cells achieved long-term survival and immune memory in the murine GL261 glioma model (Zhang et al., 2014). In this study, a TLR1/TLR2 agonist enhanced the survival and function of administered T cells and altered the glioma microenvironment by simultaneously elevating the number of $\mathrm{CD}^{+}$positive $\mathrm{T}$ cells and down-regulating the number of immunosuppressive myeloid-derived suppressor cells (MDSCs). This effect was TLR2 dependent. In other experiments, endogenous TLR2 agonist HMGB1, released from glioma cells by targeted treatment with gancyclovir, activated DCs and facilitated therapy (Curtin et al., 2009). Under this treatment strategy, nearly half of the mice bearing intracranial GL261 gliomas achieved long-term survival and anti-glioma immunological memory in a TLR2 dependent manner. The therapy stimulated the clonal expansion of glioma antigen specific T cells in tumor bearing mice, with a significantly higher proportion of $\mathrm{T}$ cell precursors releasing IFNY in response to glioma antigen. 


\section{TLR3}

In the murine CNS model, poly(I: C) enhanced induction, expansion, and CNS homing of antigen specific $T$ cells. $\mathrm{CD}^{+}$positive $\mathrm{T}$ cells in CLNs displayed higher expression of alpha4 beta1 integrin (very late activation antigen 4, VLA4), a molecule that favors CNS tropism (Calzascia et al., 2005). Poly(I:C) facilitated tumor antigen specific T cell homing via VLA4 up-regulation. In addition, poly(I:C) stimulated T cells to produce more IFN- $y$ in the intracranial glioma microenvironment (Zhu et al., 2007).

\section{TLR4}

Two TLR4 agonists, LPS and Spirulina complex polysaccharide, have demonstrated efficacy in mice with subcutaneous implantation of DBT and RSV-M gliomas, respectively (Chicoine et al., 2007; Kawanishi et al., 2013). TLR4 signaling was activated and a variety of immune cell types, including $C D 4^{+} \mathrm{T}$, $\mathrm{CD}^{+} \mathrm{T}$, NK cells, and macrophages, were exploited in tumor suppression. One major difference between the mechanisms of glioma suppression utilized by LPS and Spirulina complex polysaccharide in glioma suppression is that LPS elevates IL-17 in mouse serum while Spirulina complex polysaccharid downregulates the cytokine. IL-17 is a pleiotropic cytokine with pro- or anti-tumor potential depending on the tumor model. In the murine glioma model, IL-17 was shown to promote glioma growth (Chicoine et al., 2007). Moreover, Spirulina complex polysaccharide was less toxic. These particular studies on TLR4 agonists also highlight the importance in general of optimizing their utility, such as lowering toxicity while maintaining antitumor activity, in a clinical setting.

\section{TLR7}

Topical administration of the TLR7 agonist imiquimod has been approved by the FDA in the treatment of skin cancers and genital warts. In one of the more unusual treatment approaches, topical administration of imiquimod (shoulder and flank) was also employed in a mouse glioma model and in fact eradicated the intracranial tumor (Xiong and Ohlfest, 2011). Topical administration in the mice depleted $C D 4^{+}$Tand $\mathrm{CD}^{+} \mathrm{T}$ cells in the peripheral blood circulation, redistributed them in mouse CLNs and brain, and reversed tumor immune suppression by significantly reducing the absolute number of Tregs in the tumor microenvironment. These responses all together led to intracranial tumor inhibition. The topical administration of imiquimod also released/activated brain infiltrating lymphocytes from the refractory state induced by the intracranial tumor (Xiong and Ohlfest, 2011). Moreover, antitumor immune memory developed in mice subcutaneously injected with imiquimod (Stathopoulos et al., 2012).

\section{TLR9}

The TLR9 agonist CpG has been shown to eradicate murine intracranial glioma when subcutaneously administered with tumor lysate and effector T cells (Wu et al., 2007). Further investigation into local administration of $\mathrm{CpG}$ analyzed the change in the balance between effector T cells and regulatory $\mathrm{T}$ cells at the tumor site. The ratio of $\mathrm{CD}^{+} \mathrm{T}$ effector cells to $\mathrm{CD}^{+}{ }^{+} \mathrm{FoxP}^{+}$Tregs in the tumor environment was shown to be increased. In CLNs, antigen-specific activation of $\mathrm{CD}^{+}$and $\mathrm{CD}^{+} \mathrm{T}$ cells was observed with $\mathrm{CpG}$ administration (Grauer et al., 2007).

Side effects, such as a transient worsening of baseline neurological symptoms resulting from brain edema (Calzascia et al., 2005; da Fonseca and Badie, 2013), occurred in the CpG clinical trial. One clinical study attempted to avoid the severe neural inflammation caused by the single high dose injection by applying $\mathrm{CpG}$ through multiple injections at a lower dose. In this study, NK cells were found to be increased and were higher than $\mathrm{CD}^{+} \mathrm{T}$ cells in the tumor. Depletion of NK cells with antibody completely abrogated the antitumor effect, while only a minor reduction in efficacy was observed after CD8 ${ }^{+}$T cell depletion (Alizadeh et al., 2010). Another important finding of this study was the significant elevation of MDSCs, but not Tregs, in the brain, blood, and spleens in response to the single high dose injection of CpGODN. This finding supports the administration of multiple low dose injections of $\mathrm{CpG}$ rather than a single high dose injection (Alizadeh et al., 2010). Other methods of drug delivery, carbon nanotube application, appeared to also enhance the efficacy of $\mathrm{CpG}$, including a survival benefit. The study also confirmed the roles of $\mathrm{CD}^{+} \mathrm{T}^{\mathrm{T}}$ cells and NK cells in the anti-glioma immune response (Zhao et al., 2011).

Based on the current literature, TLR3 and TLR7 agonists may be generally categorized as "safe" agonists to use in glioma therapy, as response is largely tumor inhibition in the absence of tumor promotion. However, evidence of TLR3 and TLR7 tumor-promotion has been reported for other cancers such as in lung, pancreas, and liver (Chatterjee et al., 2014; Eigenbrod and Dalpke, 2013; Eiro et al., 2014; Zhan et al., 2014). Further investigation is, therefore, necessary to confirm these observations. In the case of TLR4 and TLR9 agonists, the recommendation is to remain cautious when considering their roles in anti-glioma therapies. Results already demonstrate that in vitro and in vivo studies do not completely overlap. One important line of investigation for the future is to perform in vivo studies of human glioma cell lines in humanized mouse models in order to fully understand the nature of the anti-tumor and pro-tumor effects of TLR4 and TLR9 agonists.

\section{CLINICAL TRIALS BASED ON TLR AGONIST THERAPY}

Biological rationale for immunotherapy in the central nervous system

The human central nervous system was once regarded as immunologically privileged. Several factors that constitute an effective immune system were thought to be absent or 
insufficient in the CNS. They included the mode of entry for immune cells which was thought to be blocked by the blood brain barrier (BBB), the lymphatic vascular system, and major histocompatibility complex (MHC) and local antigen presenting cells (Muldoon et al., 2013). Current understanding has replaced the previous concept of the CNS immune system, as a result of the discovery of some CNS specific mechanisms for eliciting immune response. First, the BBB is compromised in pathological conditions such as inflammation and tumor development, and under pharmacological modification with BBB specific disruptive agents (Bartus et al., 1996; Boskovitz et al., 2004; Elliott et al., 1996; Stamatovic et al., 2008; Wang and Casley-Smith, 1989; Wolburg et al., 2005). Any one of these conditions thus theoretially provides the opportunity for entry of both immune cells and therapeutic monoclonal antibodies. Second, instead of lymphatic drainage in the traditional sense, CNS immunological contact with its draining CLN is established through the perineural lymphatic pathway (Foldi, 1999) and the prelymphatic-lymphatic system (Wang and Casley-Smith,
1989). Third, CNS residing microglia, with a poor antigen presentation ability in the resting state, could be stimulated by an underlying pathology in the CNS to interact with T cells and become effective APCs (Yang et al., 2010). In addition, macrophages and especially DCs, though limited in the brain parenchyma, are abundant in choroid plexus epithelium and serve as strong APCs under certain biological and pathological conditions (Hussain and Heimberger, 2005; Serot et al., 1997). Finally, the CNS has its own immune surveillance system. The immune cells enter the cerebrospinal fluid (CSF) at the position in the choroid plexus where CSF is produced, and CSF circulation establishes immune surveillance (Provencio et al., 2005).

\section{Current status of clinical trials based on TLR agonist therapy}

An important aspect of the utilization of TLRs in glioma clinical trials is the application of TLR agonists as single agents to suppress the tumor. A number of trials have been designed

Table 1. Clinical trials in glioma immunotherapy with TLR agonists

\begin{tabular}{|c|c|c|c|c|c|}
\hline Diagnosis & TLR target & Agent & Phase & Status & Trial \\
\hline GBM & TLR3 & PolyICLC/ APVAC1 vaccine & 1 & Not recruiting & NCT02149225 \\
\hline AllI, GBM & TLR3 & PolyICLC/IMA950 & $1 / 2$ & Recruiting & NCT01920191 \\
\hline Recurrent Ped LGG & TLR3 & PolylCLC & 2 & Recruiting & NCT01188096 \\
\hline Recurrent AlI, OII, OAll & TLR3 & PolyICLC/glioma peptide & 0 & $\begin{array}{l}\text { Not } \\
\text { recruiting }\end{array}$ & NCT00874861 \\
\hline Recurrent GBM, AIII, OIII, OAIII & TLR3 & PolyICLC/DC vaccine & $1 / 2$ & $\begin{array}{l}\text { Not } \\
\text { recruiting }\end{array}$ & NCT00766753 \\
\hline AllI, OAIII, GBM & TLR3/TLR7 & $\begin{array}{l}\text { PolylCLC/Resiquimod/DC } \\
\text { vaccine }\end{array}$ & 2 & Recruiting & NCT01204684 \\
\hline $\begin{array}{l}\text { Ped pontine glioma, ped HGG, } \\
\text { recurrent ped LGG, recurrent } \\
\text { ped HGG }\end{array}$ & TLR3 & PolyICLC/ glioma peptide & - & Recruiting & NCT01130077 \\
\hline GBM/post operative & TLR3 & PolyICLC/radiation & 2 & Completed & NCT00052715 \\
\hline AllI, OIII, OAIII & TLR3 & PolyICLC & 2 & Unknown & NCT00058123 \\
\hline GBM/post operative & TLR3 & $\begin{array}{l}\text { PolyICLC/Temozolomide/ } \\
\text { radiation }\end{array}$ & 2 & Completed & NCT00262730 \\
\hline High risk All, OAll & TLR7 & $\begin{array}{l}\text { Imiquimod/Tumor lysate } \\
\text { vaccine }\end{array}$ & 0 & Recruiting & NCT01678352 \\
\hline Recurrent Ped ependymoma & TLR7 & Imiquimod/glioma peptide & 2 & Recruiting & NCT01795313 \\
\hline Recurrent GBM, Alll & TLR7 & $\begin{array}{l}\text { Imiquimod/DC vaccine/ } \\
\text { Tumor lysate }\end{array}$ & 2 & Recruiting & NCT01808820 \\
\hline GBM & TLR7 & $\begin{array}{l}\text { Imiquimod/SL-701 vaccine/ } \\
\text { Leukine } 150 \text { micrograms }\end{array}$ & $1 / 2$ & Recruiting & NCT02078648 \\
\hline $\begin{array}{l}\text { GBM, Alll, Medulloblastoma, } \\
\text { Ependymoma }\end{array}$ & TLR7 & $\begin{array}{l}\text { Imiquimod/DC vaccine } \\
\text { (tumor stem cell loaded) }\end{array}$ & 1 & Completed & NCT01171469 \\
\hline PedGBM, HGG & TLR7 & $\begin{array}{l}\text { Imiquimod/DC vaccine/ } \\
\text { Tumor lysate }\end{array}$ & 1 & Recruiting & NCT01902771 \\
\hline GBM & TLR9 & CpG-ODN & 2 & Completed & NCT00190424 \\
\hline
\end{tabular}

A astrocytoma, O oligodendroglioma, OA oligoastrocytoma, GBM glioblastoma multiforme, ped pediatric, LGG low grade glioma, HGG high grade glioma. 


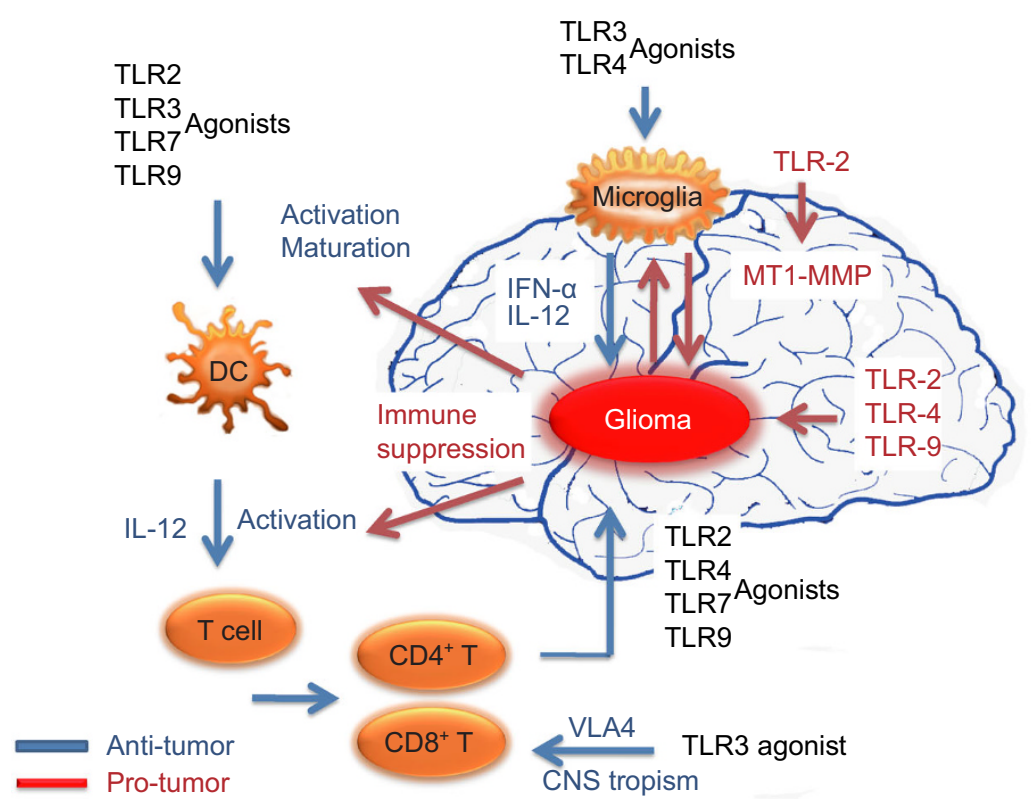

Figure 1. TLR agonists stimulate both anti- and pro-glioma processes. Biological activities initiated through TLR pathways are dependent on the receptor stimulated, the cell type, and the microenvironment. In the anti-glioma process, TLR agonists encourage the development of an immune environment by directly stimulating DC and T cell maturation. In addition, TLR activation in these cell types opposes the immune suppressive environment by favoring CNS tropism. Migration elevates the numbers of these cells in the CNS tumor and CLN and initiates anti-glioma immunity. TLR agonists also induce microglia isolated from primary gliomas to produce inflammatory cytokines and acquire anti-glioma activity. In contrast, activation of TLR2, TLR4, and TLR9 in microglia facilitates proglioma activities, such as tumor cell growth, invasion, and migration.

based on this strategy, and some have supplemented TLR treatment with chemo- and radio-therapies. To date, three clinical trials have been completed with published results.

One CpG phase II clinical trial has been completed for patients with recurrent GBM. A total of 34 patients with recurrent GBM were enrolled; $\mathrm{CpG}$ was administered intracerebrally to $31 / 34$ patients. Overall, the therapy was well tolerated. The 6-month progression free-survival (19\%) was increased compared to the control group (3\%). One partial response $(-78 \%)$ and 3 minor responses $(-33 \%,-26 \%$, and $-25 \%)$ were observed. Adverse events associated with therapy included lymphopenia, mild fever, seizures, and worsening of baseline neurological symptoms (Carpentier et al., 2010).

Two Phase II polyICLC (a chemically and biologically stable form of poly(l:C)) trials have been completed. In one clinical trial, which evaluated the therapeutic efficacy of polyICLC in combination with irradiation for newly diagnosed GBM patients, muscle injection of polyICLC was administered to 30 patients. The treatment achieved a survival benefit compared to historical studies using irradiation without chemotherapy, but no survival benefit compared to irradiation with adjuvant nitrosourea or non-temozolomide chemotherapy. Toxicity was generally minor, but could be accompanied by fatigue, leucopenia, lymphocytopenia, and pain at the site of injection (Butowski et al., 2009). PolyICLC was further tested as adjuvant therapy on postoperative glioblastoma patients in combination with the current standard for treatment, irradiation and temozolomide (TMZ). At the endpoint of the trial, the overall survival at 12 and 18 months was greater than in the previous EORTC phase III trial in which patients were treated with irradiation and TMZ (Rosenfeld et al., 2010; Stupp et al., 2005).

In many other clinical trials, TLR agonists are designed to be administered with other glioma vaccines as adjuvant. Most of these clinical trials focus on tumor antigens and DCs (Jackson et al., 2013). Several antigens or glioma specific molecules have been characterized and utilized in glioma vaccines, including epidermal growth factor receptor variant III (EGFRvIII), IL-13 receptor $\alpha 2$, IL-4 receptor, and heat shock protein (HSP) gp96 (Eguchi et al., 2006; Graner et al., 2007; Kawakami et al., 2000; Li et al., 2010). However, instead of single antigens, many more designs utilize a mixture of antigens, namely tumor lysate that contains most of the glioma antigens that have been discovered. Furthermore, regarding DCs in vaccines, the most important APCs are artificially derived in an in vitro environment to enhance contact between the cells and the antigens. TLR agonists are thereby designed into the procedure to augment the therapeutic effect.

Table 1 lists all current clinical trials for TLR agonists in glioma immunotherapy. Most of these trials are still at the 
patient recruiting stage. The trials are mainly focused on the therapeutic utility of agonists for TLR3, TLR7, and TLR9. The targets of the immunotherapy include primary and recurrent gliomas of different grades and pathology from pediatric as well as adult patients. Identifier numbers for the clinical trial are listed in the table, and for more detailed information, please refer to the government website: http://www.clinicaltrials.gov.

Finally, new developments emerging from studies on TLR agonists in many other tumor models may also be relevant to immunotherapy for glioma patients. Firstly, tumor antigens for vaccines are derived from lysates of cancer stem cells in order to more aggressively generate an anti-tumor response. In a murine model of triple negative breast cancer, $\mathrm{CpG}$ was administered as an adjuvant in a vaccine based on a breast cancer stem cell lysate, which achieved tumor regression and a survival benefit (Liu et al., 2013). Secondly, combination therapies of different TLR agonists have been reported to exert synergistic stimulatory effects upon anti-tumor immune response. Co-delivery of 3 M-052 (TLR7, TLR8 agonist) and $\mathrm{CpG}$ ODN via intratumoral injection has led to complete rejection of large tumors (colon cancer and melanoma) in murine models, while delivery of $3 \mathrm{M}-052$ or $\mathrm{CpG}$ ODN alone only reduced the tumor growth rate (Zhao et al., 2014). Thirdly, TLR agonists have been combined with therapeutic agents targeting certain immunosuppressive factors. BCG administered with IL-10 receptor 1 monoclonal antibody resulted in enhanced anti-tumor immunity in a murine model of metastatic bladder cancer, which had been initially resistant to BCG treatment alone (Newton et al., 2014). Similar findings were reported from a study on a murine lymphoma model treated with $\mathrm{CpG}$ and IL-10 siRNA (Pradhan et al., 2014). Lastly, efforts are being made to enhance anti-tumor response with improvements in the delivery system for TLR agonists, such as with cationic liposomes. Cationic liposomes have been found to potentiate anti-tumor immune responses induced by poly $(\mathrm{l}: \mathrm{C})$ in murine melanoma models (Hansen et al., 2012), and to engage TLR4 on tumor associated macrophages that also resulted in anti-tumor immune response (Huang et al., 2013). A more novel approach for delivery exploited a type of nanogel which was loaded with CpG ODN or polyICLC and peptide antigen. This combination was reported to be capable of specifically delivering the vaccines to the draining lymph nodes and preferentially activating the medullary macrophages (Muraoka et al., 2014), which resulted in effective cross-priming of vaccine specific effector $T$ cells and antitumor activities in murine colon cancer and sarcoma models.

\section{CONCLUSIONS}

Immunotherapy designed against human gliomas is fundamentally challenged by the sophisticated interactions between gliomas and their immunological environments. In addition, TLRs are distributed widely among cell types and can elicit completely different responses depending on the cell and the environment (Fig. 1). Most studies fractionate these differences by focusing on one TLR and one tumor cell type as the target for study. However, the nature of the widespread expression and the combined effect of TLRs and TLR agonists underlie the necessity for a more comprehensive understanding of their function in glioma therapies. Results from many biological disciplines have contributed to our current molecular and clinical understanding, but information is still lacking, and many questions await answers. What is the general distribution of glioma TLR expression on an epidemiological scale? What are the real clinical effects of TLR agonists on glioma patients? How do we select and administer TLR agonists and maximize their anti-tumor effect while minimizing their pro-tumor potential? Is it possible or necessary to adopt a combination(s) of different TLRs and agonists in glioma treatment? Answering these questions requires further molecular and clinical investigation, which will undoubtedly lead to new, perhaps groundbreaking insights for the clinical management of human glioma.

\section{ACKNOWLEDGEMENTS}

This work was supported by the National Major Scientific and Technological Special Project for "Significant New Drugs Development" during the Twelfth Five-year Plan Period (2013ZX09102032), and the Key Scientific Project of Jilin Province (20140204024YY). We sincerely apologize to the authors whose work was not cited in this review due to the space limitations.

\section{ABBREVIATIONS}

$\mathrm{APC}$, antigen presenting cell; BBB, blood brain barrier; BMDC, bone marrow-derived dendritic cells; CLN, cervical lymphnode; CNS, central nervous system; CSF, cerebrospinal fluid; DC, dendritic cell; EGFR, epidermal growth factor receptor; HMGB1, high mobility group box 1; HSP, heat shock protein; LPS, lipid polysaccharide; $\mathrm{mDC}$, myeloid dendritic cell; MHC, major histocompatibility complex; MyD88, myeloid differentiation factor 88; TLR, Toll-like receptor.

\section{COMPLIANCE WITH ETHICS GUIDELINES}

Shuanglin Deng, Shan Zhu, Yuan Qiao, Yongjun Liu, Wei Chen, Gang Zhao, and Jingtao Chen declare that they have no conflict of interest.

This article does not contain any studies with human or animal subjects performed by any of the authors.

\section{OPEN ACCESS}

This article is distributed under the terms of the Creative Commons Attribution License which permits any use, distribution, and reproduction in any medium, provided the original author(s) and the source are credited.

\section{REFERENCES}

Adams S, O'Neill DW, Nonaka D, Hardin E, Chiriboga L, Siu K, Cruz CM, Angiulli A, Angiulli F, Ritter E et al (2008) Immunization of 
malignant melanoma patients with full-length NY-ESO-1 protein using TLR7 agonist imiquimod as vaccine adjuvant. J Immunol 181:776-784

Agrawal S, Gupta S (2011) TLR1/2, TLR7, and TLR9 signals directly activate human peripheral blood naive and memory B cell subsets to produce cytokines, chemokines, and hematopoietic growth factors. J Clin Immunol 31:89-98

Akira S, Takeda K (2004) Toll-like receptor signalling. Nat Rev Immunol 4:499-511

Ali S, Curtin JF, Zirger JM, Xiong W, King GD, Barcia C, Liu C, Puntel M, Goverdhana S, Lowenstein PR et al (2004) Inflammatory and anti-glioma effects of an adenovirus expressing human soluble Fms-like tyrosine kinase 3 ligand (hsFlt3L): treatment with hsFlt3L inhibits intracranial glioma progression. Mol Ther 10:1071-1084

Alizadeh D, Zhang L, Brown CE, Farrukh O, Jensen MC, Badie B (2010) Induction of anti-glioma natural killer cell response following multiple low-dose intracerebral CpG therapy. Clin Cancer Res 16:3399-3408

Anandasabapathy N, Victora GD, Meredith M, Feder R, Dong B, Kluger C, Yao K, Dustin ML, Nussenzweig MC, Steinman RM et al (2011) Flt3L controls the development of radiosensitive dendritic cells in the meninges and choroid plexus of the steadystate mouse brain. J Exp Med 208:1695-1705

Anderson KV, Jurgens G, Nusslein-Volhard C (1985) Establishment of dorsal-ventral polarity in the Drosophila embryo: genetic studies on the role of the Toll gene product. Cell 42:779-789

Arunkumar N, Liu C, Hang H, Song W (2013) Toll-like receptor agonists induce apoptosis in mouse B-cell lymphoma cells by altering NF-kappaB activation. Cell Mol Immunol 10:360-372

Asea A, Rehli M, Kabingu E, Boch JA, Baré O, Auron PE, Stevenson MA, Calderwood SK (2002) Novel signal transduction pathway utilized by extracellular HSP70 role of Toll-like receptor (TLR) 2 and TLR4. J Biol Chem 277:15028-15034

Bartus RT, Elliott P, Hayward N, Dean R, McEwen EL, Fisher SK (1996) Permeability of the blood brain barrier by the bradykinin agonist, RMP-7: evidence for a sensitive, auto-regulated, receptor-mediated system. Immunopharmacology 33:270-278

Bernasconi NL, Onai N, Lanzavecchia A (2003) A role for Toll-like receptors in acquired immunity: up-regulation of TLR9 by BCR triggering in naive $B$ cells and constitutive expression in memory B cells. Blood 101:4500-4504

Boskovitz A, Wikstrand CJ, Kuan CT, Zalutsky MR, Reardon DA, Bigner DD (2004) Monoclonal antibodies for brain tumour treatment. Expert Opin Biol Ther 4:1453-1471

Brat DJ, Bellail AC, Van Meir EG (2005) The role of interleukin-8 and its receptors in gliomagenesis and tumoral angiogenesis. Neuro Oncol 7:122-133

Brody JD, Ai WZ, Czerwinski DK, Torchia JA, Levy M, Advani RH, Kim YH, Hoppe RT, Knox SJ, Shin LK et al (2010) In situ vaccination with a TLR9 agonist induces systemic lymphoma regression: a phase I/II study. J Clin Oncol 28:4324-4332

Butowski N, Chang SM, Junck L, DeAngelis LM, Abrey L, Fink K, Cloughesy T, Lamborn KR, Salazar AM, Prados MD (2009) A phase II clinical trial of poly-ICLC with radiation for adult patients with newly diagnosed supratentorial glioblastoma: a North American Brain Tumor Consortium (NABTC01-05). J Neurooncol 91:175-182
Calzascia T, Masson F, Di Berardino-Besson W, Contassot E, Wilmotte R, Aurrand-Lions M, Rüegg C, Dietrich P-Y, Walker PR (2005) Homing phenotypes of tumor-specific CD8 T cells are predetermined at the tumor site by crosspresenting APCs. Immunity 22:175-184

Caron G, Duluc D, Fremaux I, Jeannin P, David C, Gascan H, Delneste $Y$ (2005) Direct stimulation of human T cells via TLR5 and TLR7/8: flagellin and R-848 up-regulate proliferation and IFN-gamma production by memory CD4 + T cells. J Immunol 175:1551-1557

Carpentier A, Metellus P, Ursu R, Zohar S, Lafitte F, Barrié M, Meng Y, Richard M, Parizot C, Laigle-Donadey F (2010) Intracerebral administration of $\mathrm{CpG}$ oligonucleotide for patients with recurrent glioblastoma: a phase II study. Neuro-oncology 12:401-408

Chatterjee S, Crozet L, Damotte D, Iribarren K, Schramm C, Alifano M, Lupo A, Cherfils-Vicini J, Goc J, Katsahian S et al (2014) TLR7 promotes tumor progression, chemotherapy resistance, and poor clinical outcomes in non-small cell lung cancer. Cancer Res 74:5008-5018

Cherfils-Vicini J, Platonova S, Gillard M, Laurans L, Validire P, Caliandro R, Magdeleinat P, Mami-Chouaib F, Dieu-Nosjean MC, Fridman WH et al (2010) Triggering of TLR7 and TLR8 expressed by human lung cancer cells induces cell survival and chemoresistance. J Clin Invest 120:1285-1297

Chicoine MR, Zahner M, Won EK, Kalra RR, Kitamura T, Perry A, Higashikubo R (2007) The in vivo antitumoral effects of lipopolysaccharide against glioblastoma multiforme are mediated in part by Toll-like receptor 4 . Neurosurgery 60:372-380 discussion 381

Chirasani SR, Leukel P, Gottfried E, Hochrein J, Stadler K, Neumann B, Oefner PJ, Gronwald W, Bogdahn U, Hau P et al (2013) Diclofenac inhibits lactate formation and efficiently counteracts local immune suppression in a murine glioma model. Int J Cancer 132:843-853

Crellin NK, Garcia RV, Hadisfar O, Allan SE, Steiner TS, Levings MK (2005) Human CD4 + T cells express TLR5 and its ligand flagellin enhances the suppressive capacity and expression of FOXP3 in CD4 + CD25 + T regulatory cells. J Immunol 175:8051-8059

Curtin JF, Liu N, Candolfi M, Xiong W, Assi H, Yagiz K, Edwards MR, Michelsen KS, Kroeger KM, Liu C et al (2009) HMGB1 mediates endogenous TLR2 activation and brain tumor regression. PLoS Med 6:e10

da Fonseca AC, Badie B (2013) Microglia and macrophages in malignant gliomas: recent discoveries and implications for promising therapies. Clin Dev Immunol 2013:264124

Echigo R, Sugimoto N, Yachie A, Ohno-Shosaku T (2012) Cannabinoids inhibit peptidoglycan-induced phosphorylation of NF-kappaB and cell growth in U87MG human malignant glioma cells. Oncol Rep 28:1176-1180

Eguchi J, Hatano M, Nishimura F, Zhu X, Dusak JE, Sato H, Pollack IF, Storkus WJ, Okada H (2006) Identification of interleukin-13 receptor a2 peptide analogues capable of inducing improved antiglioma CTL responses. Cancer Res 66:5883-5891

Eigenbrod T, Dalpke AH (2013) TLR7 inhibition: a novel strategy for pancreatic cancer treatment? Jak-Stat 2:e23011

Eiro N, Altadill A, Juarez LM, Rodriguez M, Gonzalez LO, Atienza S, Bermudez S, Fernandez-Garcia B, Fresno-Forcelledo MF, Rodrigo $L$ et al (2014) Toll-like receptors 3, 4 and 9 in hepatocellular 
carcinoma: Relationship with clinicopathological characteristics and prognosis. Hepatol Res: Off J Japan Soc Hepatol 44:769778

Elliott PJ, Hayward NJ, Dean RL, Bartus RT (1996) Dissociation of blood-brain barrier permeability and the hypotensive effects of the bradykinin B2 agonist, RMP-7. Immunopharmacology 33:205-208

Foldi M (1999) The brain and the lymphatic system revisited. Lymphology 32:40-44

Graner MW, Cumming RI, Bigner DD (2007) The heat shock response and chaperones/heat shock proteins in brain tumors: surface expression, release, and possible immune consequences. J Neurosci 27:11214-11227

Grauer O, Poschl P, Lohmeier A, Adema GJ, Bogdahn U (2007) Tolllike receptor triggered dendritic cell maturation and IL-12 secretion are necessary to overcome T-cell inhibition by gliomaassociated TGF-beta2. J Neurooncol 82:151-161

Gupta P, Ghosh S, Nagarajan A, Mehta VS, Sen E (2013) beta-defensin3 negatively regulates TLR4-HMGB1 axis mediated HLA-G expression in IL-1beta treated glioma cells. Cell Signal 25:682-689

Haghparast, A., Heidari Kharaji, M., and Malvandi, A.M. (2011). Down-regulation of CD14 transcripts in human glioblastoma cell line U87 MG. Iran J Immunol 8

Hansen J, Lindenstrom T, Lindberg-Levin J, Aagaard C, Andersen P, Agger EM (2012) CAF05: cationic liposomes that incorporate synthetic cord factor and poly(l:C) induce CTL immunity and reduce tumor burden in mice. Cancer Immunol, Immunothers CII 61:893-903

Herrmann A, Cherryholmes G, Schroeder A, Phallen J, Alizadeh D, Xin H, Wang T, Lee H, Lahtz C, Swiderski P et al (2014) TLR9 is critical for glioma stem cell maintenance and targeting. Cancer Res Hornung V, Rothenfusser S, Britsch S, Krug A, Jahrsdorfer B, Giese T, Endres S, Hartmann G (2002) Quantitative expression of tolllike receptor 1-10 mRNA in cellular subsets of human peripheral blood mononuclear cells and sensitivity to CpG oligodeoxynucleotides. J Immunol 168:4531-4537

Huang B, Zhao J, Shen S, Li H, He KL, Shen GX, Mayer L, Unkeless J, Li D, Yuan Y et al (2007) Listeria monocytogenes promotes tumor growth via tumor cell toll-like receptor 2 signaling. Cancer Res 67:4346-4352

Huang Z, Yang Y, Jiang Y, Shao J, Sun X, Chen J, Dong L, Zhang J (2013) Anti-tumor immune responses of tumor-associated macrophages via toll-like receptor 4 triggered by cationic polymers. Biomaterials 34:746-755

Hussain SF, Heimberger AB (2005) Immunotherapy for human glioma: innovative approaches and recent results. Expert Rev Anticancer Ther 5:777-790

Hussain SF, Yang D, Suki D, Aldape K, Grimm E, Heimberger AB (2006a) The role of human glioma-infiltrating microglia/macrophages in mediating antitumor immune responses. Neuro Oncol 8:261-279

Hussain SF, Yang D, Suki D, Grimm E, Heimberger AB (2006b) Innate immune functions of microglia isolated from human glioma patients. J Transl Med 4:15

Jackson C, Ruzevick J, Brem H, Lim M (2013) Vaccine strategies for glioblastoma: progress and future directions. Immunotherapy 5:155-167
Kabelitz D (2007) Expression and function of Toll-like receptors in T lymphocytes. Curr Opin Immunol 19:39-45

Karman J, Ling C, Sandor M, Fabry Z (2004) Initiation of immune responses in brain is promoted by local dendritic cells. J Immunol 173:2353-2361

Kawakami K, Leland P, Puri RK (2000) Structure, function, and targeting of interleukin 4 receptors on human head and neck cancer cells. Cancer Res 60:2981-2987

Kawanishi Y, Tominaga A, Okuyama H, Fukuoka S, Taguchi T, Kusumoto Y, Yawata T, Fujimoto Y, Ono S, Shimizu K (2013) Regulatory effects of Spirulina complex polysaccharides on growth of murine RSV-M glioma cells through Toll-like receptor 4. Microbiol Immunol 57:63-73

Kees T, Lohr J, Noack J, Mora R, Gdynia G, Todt G, Ernst A, Radlwimmer B, Falk CS, Herold-Mende C et al (2012) Microglia isolated from patients with glioma gain antitumor activities on poly (I:C) stimulation. Neuro Oncol 14:64-78

Kepp O, Galluzzi L, Martins I, Schlemmer F, Adjemian S, Michaud M, Sukkurwala AQ, Menger L, Zitvogel L, Kroemer G (2011) Molecular determinants of immunogenic cell death elicited by anticancer chemotherapy. Cancer Metastasis Rev 30:61-69

Kjellman C, Olofsson SP, Hansson O, Von Schantz T, Lindvall M, Nilsson I, Salford LG, Sjogren HO, Widegren B (2000) Expression of TGF-beta isoforms, TGF-beta receptors, and SMAD molecules at different stages of human glioma. Int J Cancer 89:251-258

Kostianovsky AM, Maier LM, Anderson RC, Bruce JN, Anderson DE (2008) Astrocytic regulation of human monocytic/microglial activation. J Immunol 181:5425-5432

Krieg AM (2006) Therapeutic potential of Toll-like receptor 9 activation. Nat Rev Drug Discov 5:471-484

Kundu SD, Lee C, Billips BK, Habermacher GM, Zhang Q, Liu V, Wong LY, Klumpp DJ, Thumbikat $P$ (2008) The toll-like receptor pathway: a novel mechanism of infection-induced carcinogenesis of prostate epithelial cells. Prostate 68:223-229

Leng L, Jiang T, Zhang Y (2012) TLR9 expression is associated with prognosis in patients with glioblastoma multiforme. J Clin Neurosci 19:75-80

Li G, Mitra S, Wong AJ (2010) The epidermal growth factor variant III peptide vaccine for treatment of malignant gliomas. Neurosurg Clin N Am 21:87-93

Li X, Liu D, Liu X, Jiang W, Zhou W, Yan W, Cen Y, Li B, Cao G, Ding $G$ et al (2012) CpG ODN107 potentiates radiosensitivity of human glioma cells via TLR9-mediated NF-kappaB activation and NO production. Tumour Biol 33:1607-1618

Liu X, Hu J, Cao W, Qu H, Wang Y, Ma Z, Li F (2013) Effects of two different immunotherapies on triple negative breast cancer in animal model. Cell Immunol 284:111-118

Louis DN, Ohgaki H, Wiestler OD, Cavenee WK, Burger PC, Jouvet A, Scheithauer BW, Kleihues P (2007) The 2007 WHO classification of tumours of the central nervous system. Acta Neuropathol 114:97-109

Mansson A, Adner M, Hockerfelt U, Cardell LO (2006) A distinct Tolllike receptor repertoire in human tonsillar B cells, directly activated by PamCSK, R-837 and CpG-2006 stimulation. Immunology 118:539-548

Maraskovsky E, Brasel K, Teepe M, Roux ER, Lyman SD, Shortman K, McKenna HJ (1996) Dramatic increase in the numbers of 
functionally mature dendritic cells in Flt3 ligand-treated mice: multiple dendritic cell subpopulations identified. J Exp Med 184:1953-1962

Medzhitov R, Preston-Hurlburt P, Janeway CA Jr (1997) A human homologue of the Drosophila Toll protein signals activation of adaptive immunity. Nature 388:394-397

Meng Y, Kujas M, Marie Y, Paris S, Thillet J, Delattre J-Y, Carpentier AF (2008) Expression of TLR9 within human glioblastoma. J Neuro-oncol 88:19-25

Muldoon LL, Alvarez JI, Begley DJ, Boado RJ, Del Zoppo GJ, Doolittle ND, Engelhardt B, Hallenbeck JM, Lonser RR, Ohlfest JR et al (2013) Immunologic privilege in the central nervous system and the blood-brain barrier. J Cereb Blood Flow Metab 33:13-21

Muraoka D, Harada N, Hayashi T, Tahara Y, Momose F, Sawada S, Mukai SA, Akiyoshi K, Shiku H (2014) Nanogel-based immunologically stealth vaccine targets macrophages in the medulla of lymph node and induces potent antitumor immunity. ACS Nano 8:9209-9218

Newton MR, Askeland EJ, Andresen ED, Chehval VA, Wang X, Askeland RW, O'Donnell MA, Luo Y (2014) Anti-interleukin-10R1 monoclonal antibody in combination with bacillus CalmetteGuerin is protective against bladder cancer metastasis in a murine orthotopic tumour model and demonstrates systemic specific anti-tumour immunity. Clin Exp Immunol 177:261-268

Nomi N, Kodama S, Suzuki M (2010) Toll-like receptor 3 signaling induces apoptosis in human head and neck cancer via survivin associated pathway. Oncol Rep 24:225-231

O'Neill LA, Bowie AG (2007) The family of five: TIR-domaincontaining adaptors in Toll-like receptor signalling. Nat Rev Immunol 7:353-364

Platten M, Kretz A, Naumann U, Aulwurm S, Egashira K, Isenmann S, Weller M (2003) Monocyte chemoattractant protein-1 increases microglial infiltration and aggressiveness of gliomas. Ann Neurol 54:388-392

Poltorak A, He X, Smirnova I, Liu MY, Van Huffel C, Du X, Birdwell D, Alejos E, Silva M, Galanos C et al (1998) Defective LPS signaling in $\mathrm{C} 3 \mathrm{H} / \mathrm{HeJ}$ and $\mathrm{C} 57 \mathrm{BL} / 10 \mathrm{ScCr}$ mice: mutations in Tlr4 gene. Science 282:2085-2088

Pradhan P, Qin H, Leleux JA, Gwak D, Sakamaki I, Kwak LW, Roy K (2014) The effect of combined IL10 siRNA and CpG ODN as pathogen-mimicking microparticles on Th1/Th2 cytokine balance in dendritic cells and protective immunity against B cell lymphoma. Biomaterials 35:5491-5504

Prins RM, Soto H, Konkankit V, Odesa SK, Eskin A, Yong WH, Nelson SF, Liau LM (2011) Gene expression profile correlates with T-cell infiltration and relative survival in glioblastoma patients vaccinated with dendritic cell immunotherapy. Clin Cancer Res 17:1603-1615

Provencio JJ, Kivisakk P, Tucky BH, Luciano MG, Ransohoff RM (2005) Comparison of ventricular and lumbar cerebrospinal fluid T cells in non-inflammatory neurological disorder (NIND) patients. J Neuroimmunol 163:179-184

Pulendran B, Lingappa J, Kennedy MK, Smith J, Teepe M, Rudensky A, Maliszewski CR, Maraskovsky E (1997) Developmental pathways of dendritic cells in vivo: distinct function, phenotype, and localization of dendritic cell subsets in FLT3 ligand-treated mice. J Immunol 159:2222-2231

Rosenfeld MR, Chamberlain MC, Grossman SA, Peereboom DM, Lesser GJ, Batchelor TT, Desideri S, Salazar AM, Ye X (2010) A multi-institution phase II study of poly-ICLC and radiotherapy with concurrent and adjuvant temozolomide in adults with newly diagnosed glioblastoma. Neuro-oncology 12:1071-1077

Salaun B, Coste I, Rissoan M-C, Lebecque SJ, Renno T (2006) TLR3 can directly trigger apoptosis in human cancer cells. J Immunol 176:4894-4901

Sarrazy V, Vedrenne N, Billet F, Bordeau N, Lepreux S, Vital A, Jauberteau MO, Desmouliere A (2011) TLR4 signal transduction pathways neutralize the effect of Fas signals on glioblastoma cell proliferation and migration. Cancer Lett 311: 195-202

Serot JM, Foliguet B, Bene MC, Faure GC (1997) Ultrastructural and immunohistological evidence for dendritic-like cells within human choroid plexus epithelium. Neuroreport 8:1995-1998

Sharma P, Bajorin DF, Jungbluth AA, Herr H, Old LJ, Gnjatic S (2008) Immune responses detected in urothelial carcinoma patients after vaccination with NY-ESO-1 protein plus BCG and GM-CSF. J Immunother 31:849-857

Shinohara H, Yagita H, Ikawa Y, Oyaizu N (2000) Fas drives cell cycle progression in glioma cells via extracellular signal-regulated kinase activation. Cancer Res 60:1766-1772

Sinha S, Koul N, Dixit D, Sharma V, Sen E (2011) IGF-1 induced HIF-1alpha-TLR9 cross talk regulates inflammatory responses in glioma. Cell Signal 23:1869-1875

Stamatovic SM, Keep RF, Andjelkovic AV (2008) Brain endothelial cell-cell junctions: how to "open" the blood brain barrier. Curr Neuropharmacol 6:179-192

Stathopoulos A, Pretto C, Devillers L, Pierre D, Hofman FM, Kruse C, Jadus M, Chen TC, Schijns VE (2012) Development of immune memory to glial brain tumors after tumor regression induced by immunotherapeutic Toll-like receptor $7 / 8$ activation. Oncoimmunology 1:298-305

Stupp R, Mason WP, van den Bent MJ, Weller M, Fisher B, Taphoorn MJ, Belanger K, Brandes AA, Marosi C, Bogdahn U et al (2005) Radiotherapy plus concomitant and adjuvant temozolomide for glioblastoma. N Engl J Med 352:987-996

Tewari R, Sharma V, Koul N, Ghosh A, Joseph C, Hossain Sk U, Sen E (2009) Ebselen abrogates TNFalpha induced pro-inflammatory response in glioblastoma. Mol Oncol 3:77-83

Tewari R, Choudhury SR, Ghosh S, Mehta VS, Sen E (2012) Involvement of TNFalpha-induced TLR4-NF-kappaB and TLR4HIF-1alpha feed-forward loops in the regulation of inflammatory responses in glioma. J Mol Med (Berl) 90:67-80

Thuringer D, Hammann A, Benikhlef N, Fourmaux E, Bouchot A, Wettstein G, Solary E, Garrido C (2011) Transactivation of the epidermal growth factor receptor by heat shock protein 90 via Toll-like receptor 4 contributes to the migration of glioblastoma cells. J Biol Chem 286:3418-3428

Vansteenkiste J, Zielinski M, Linder A, Dahabre J, Esteban E, Malinowski W, Jassem J, Passlick B, Lehmann F, Brichard V (2007) Final results of a multi-center, double-blind, randomized, placebo-controlled phase II study to assess the efficacy of 
MAGE-A3 immunotherapeutic as adjuvant therapy in stage IB/II non-small cell lung cancer (NSCLC). J Clin Oncol 25:7554

Vermorken JB, Claessen AM, van Tinteren H, Gall HE, Ezinga R, Meijer S, Scheper RJ, Meijer CJ, Bloemena E, Ransom JH et al (1999) Active specific immunotherapy for stage II and stage III human colon cancer: a randomised trial. Lancet 353:345-350

Vinnakota K, Hu F, Ku MC, Georgieva PB, Szulzewsky F, Pohlmann A, Waiczies S, Waiczies H, Niendorf T, Lehnardt S et al (2013) Toll-like receptor 2 mediates microglia/brain macrophage MT1MMP expression and glioma expansion. Neuro Oncol 15:14571468

Walenta S, Mueller-Klieser WF (2004) Lactate: mirror and motor of tumor malignancy. Semin Radiat Oncol 14:267-274

Wang HJ, Casley-Smith JR (1989) Drainage of the prelymphatics of the brain via the adventitia of the vertebral artery. Acta Anat (Basel) 134:67-71

Wang C, Cao S, Yan Y, Ying Q, Jiang T, Xu K, Wu A (2010) TLR9 expression in glioma tissues correlated to glioma progression and the prognosis of GBM patients. BMC Cancer 10:415

Weller RO, Djuanda E, Yow HY, Carare RO (2009) Lymphatic drainage of the brain and the pathophysiology of neurological disease. Acta Neuropathol 117:1-14

Wolburg H, Wolburg-Buchholz K, Engelhardt B (2005) Diapedesis of mononuclear cells across cerebral venules during experimental autoimmune encephalomyelitis leaves tight junctions intact. Acta Neuropathol 109:181-190

Wu A, Oh S, Gharagozlou S, Vedi RN, Ericson K, Low WC, Chen W, Ohlfest JR (2007) In vivo vaccination with tumor cell lysate plus CpG oligodeoxynucleotides eradicates murine glioblastoma. $\mathrm{J}$ Immunother 30:789-797

Xiong Z, Ohlfest JR (2011) Topical imiquimod has therapeutic and immunomodulatory effects against intracranial tumors. J Immunother (Hagerstown, Md: 1997) 34:264
Yang I, Han SJ, Kaur G, Crane C, Parsa AT (2010) The role of microglia in central nervous system immunity and glioma immunology. J Clin Neurosci 17:6-10

Zarember KA, Godowski PJ (2002) Tissue expression of human Tolllike receptors and differential regulation of Toll-like receptor mRNAs in leukocytes in response to microbes, their products, and cytokines. J Immunol 168:554-561

Zhan Z, Xie X, Cao H, Zhou X, Zhang XD, Fan H, Liu Z (2014) Autophagy facilitates TLR4- and TLR3-triggered migration and invasion of lung cancer cells through the promotion of TRAF6 ubiquitination. Autophagy 10:257-268

Zhang Y, Luo F, Li A, Qian J, Yao Z, Feng X, Chu Y (2014) Systemic injection of TLR1/2 agonist improves adoptive antigen-specific $\mathrm{T}$ cell therapy in glioma-bearing mice. Clin Immunol 154:26-36

Zhao JX, Yang LP, Wang YF, Qin LP, Liu DQ, Bai CX, Nan X, Shi SS, Pei XJ (2007) Gelatinolytic activity of matrix metalloproteinase-2 and matrix metalloproteinase- 9 in rat brain after implantation of 9L rat glioma cells. Eur J Neurol 14:510-516

Zhao D, Alizadeh D, Zhang L, Liu W, Farrukh O, Manuel E, Diamond DJ, Badie B (2011) Carbon nanotubes enhance CpG uptake and potentiate antiglioma immunity. Clin Cancer Res 17:771-782

Zhao BG, Vasilakos JP, Tross D, Smirnov D, Klinman DM (2014) Combination therapy targeting toll like receptors 7,8 and 9 eliminates large established tumors. J Immunother Cancer 2:12

Zhu X, Nishimura F, Sasaki K, Fujita M, Dusak JE, Eguchi J, Fellows-Mayle W, Storkus WJ, Walker PR, Salazar AM et al (2007) Toll like receptor-3 ligand poly-ICLC promotes the efficacy of peripheral vaccinations with tumor antigen-derived peptide epitopes in murine CNS tumor models. J Transl Med $5: 10$ 